\title{
Analysis of energy absorption characteristics of corrugated top beam of anti-impact hydraulic support
}

\section{JUN MAO}

Liaoning Technical University

Chenghu GUO ( $\nabla 1669733517 @ q q . c o m$ )

Liaoning Technical University

MIAO XIE

Liaoning Technical University

\section{Research Article}

Keywords: masonry robot lifting platform, Active disturbance rejection control, Feedforward, Deviation compensation, Leveling system

Posted Date: July 26th, 2021

DOl: https://doi.org/10.21203/rs.3.rs-677210/v1

License: (c) (i) This work is licensed under a Creative Commons Attribution 4.0 International License. Read Full License 


\section{Research on Electro-hydraulic servo active disturbance}

rejection control strategy for lifting platform of masonry robot JUN MAO' ${ }^{1}$, Chenghu GUO' ${ }^{1}$ MIAO XIE ${ }^{1}$

${ }^{1}$ Faculty of Mechanical Engineering; Liaoning Technical University, fuxin,123000, China;

Corresponding author: Chenghu GUO (e-mail: 1669733517@qq.com).

This work was supported by the National Natural Science Foundation of China (51774162) and National Key R\&D Program Project (2017YFC0804305).

The authors declare that they have no known competing financial interests or personal relationships that could have appeared to influence the work reported in this paper.

Abstract: To solve the problem that the response of the walking platform of bricklaying robot is slow and uncertain factors such as load change and friction of hydraulic cylinder affect the adjustment accuracy, an electro-hydraulic servo system with four hydraulic cylinders is designed. The system is an improved ADRC method. The available information of the whole system is fully considered, and the piston rod position deviations of the hydraulic cylinder is taken as the input of the whole controller to reduce the phase lag caused by the extended observer and improve the response speed of the control system. The position deviations of the piston rod in a cylinder is compensated by observation, and the high-order term and uncertain disturbance in the whole control system are defined as total disturbance, so the structure of the controller is simplified appropriately. Finally, MATLAB and AMESim are used for simulation analysis. The simulation results show that the improved ADRC method can significantly improve the response speed of the system and the suppression of uncertain disturbance. This research provides a theoretical basis for the research of masonry robot mobile platforms.

Keywords: masonry robot lifting platform; Active disturbance rejection control; Feedforward; Deviation compensation; Leveling system Introduction

The electro-hydraulic servo control system is used in the lifting platform of bricklaying robots because of its advantages of high-power density ratio, lightweight, small volume, and high transmission efficiency. However, because the Electro-hydraulic servo system is a typical nonlinear system, there are many factors, such as model uncertainty, parameter perturbation, complex disturbance, load change, and so on, which affect the control accuracy, tracking performance, and anti-interference performance of the Electro-hydraulic servo position system. The traditional PID control strategy has some disadvantages, such as lag effect, and easily produce overshoot and oscillation.

Because of the above factors, optimization measures are proposed at home and abroad, which improve the control quality and robustness of the system to a certain extent. However, it is difficult to obtain an accurate mathematical model of the control object when considering the internal and external disturbances, modeling deviations, and other related uncertain factors. At the same time, due to the constraints of sensor cost and acquisition accuracy, only the required state information can be obtained through the displacement of the piston of the hydraulic cylinder, which increases the calculation amount of the controller, increases the difficulty of the design, and makes the algorithm not suitable for implementation, even leads to the failure of the control strategy.

With the emergence of active disturbance rejection control (ADRC), the precise model of 
controlled object is no longer needed, and the control of nonlinear unknown model system has certain robustness, reliability, and disturbance rejection ability. It has a unique advantage for the system with nonlinear dynamic change, modeling deviations, and other factors.

ADRC method mostly selects the order of ADRC according to the order of the system, while the Electro-hydraulic servo position system is a typical high-order nonlinear complex system. At present, the vast majority of the domestic and foreign use the third-order ADRC algorithm, which makes the theoretical analysis of the controller difficult and the parameter tuning more complex, This makes ADRC bring great inconvenience to the practical engineering application of electrohydraulic servo position system. In addition, nonlinear ADRC is more efficient than linear ADRC for nonlinear and time-varying parameter systems, and it is relatively insensitive to the initial deviations. Therefore, it is necessary to fully explore the advantages of nonlinear ADRC, extend the scope of application of the controller, and study and derive the optimal order for the controlled object, so that it has higher control performance, The complex problem of parameter setting is simplified.

Therefore, to solve the problems of parameter uncertainty and unknown disturbance in the Electro-hydraulic servo system, and simplify the structure of nonlinear active disturbance rejection controller for control object, an improved nonlinear active disturbance rejection control method based on an electro-hydraulic servo position system is proposed. The first-order nonlinear active disturbance rejection controller (ADRC) is designed based on the input-output response characteristics of the valve control system. The input-output deviations of the system are taken as the input of the controller by making full use of the known information of the system, to reduce the phase lag caused by the observer and improve the fast response of the system; The high order derivative term and external unknown disturbance of the system are regarded as the "total disturbance" of the system. The order of ADRC used in the electro-hydraulic servo position system is reduced from the third order to the first order, which makes the design difficult and easy to implement. It provides a reference for the application of ADRC in Electro-hydraulic servo control. Finally, through simulation and comparison with PID control, the improved ADRC can effectively improve the rapidity and anti-interference ability of the system and reduce the tracking deviations. 1 system mathematical model

\section{1 composition of electro-hydraulic position servo system}

The composition of the electro-hydraulic servo control system is shown in Figure 1. Its position loop is the basic link of the system, mainly including the controller, electro-hydraulic servo valve, hydraulic cylinder, load, and displacement sensor. The block diagram of the electro-hydraulic servo position control system is shown in Figure 1.

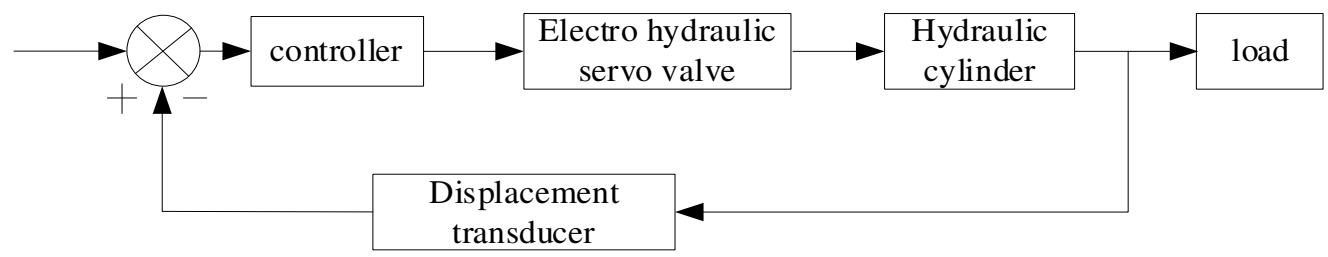

Figure 1 control schematic diagram of Electro-hydraulic position servo system 1.2 mathematical model of electro-hydraulic position servo system

For the electro-hydraulic servo position system, on the premise of ensuring the system stability, it is expected that the system response can have better rapidity and steady-state accuracy, to realize the accurate tracking of the given position signal by the position closed-loop system. The working 
principle diagram of the asymmetric valve-controlled hydraulic cylinder is shown in Figure 2. Due to the influence of the asymmetry of the hydraulic cylinder and the load elasticity, It causes serious asymmetry in the process of scaling.

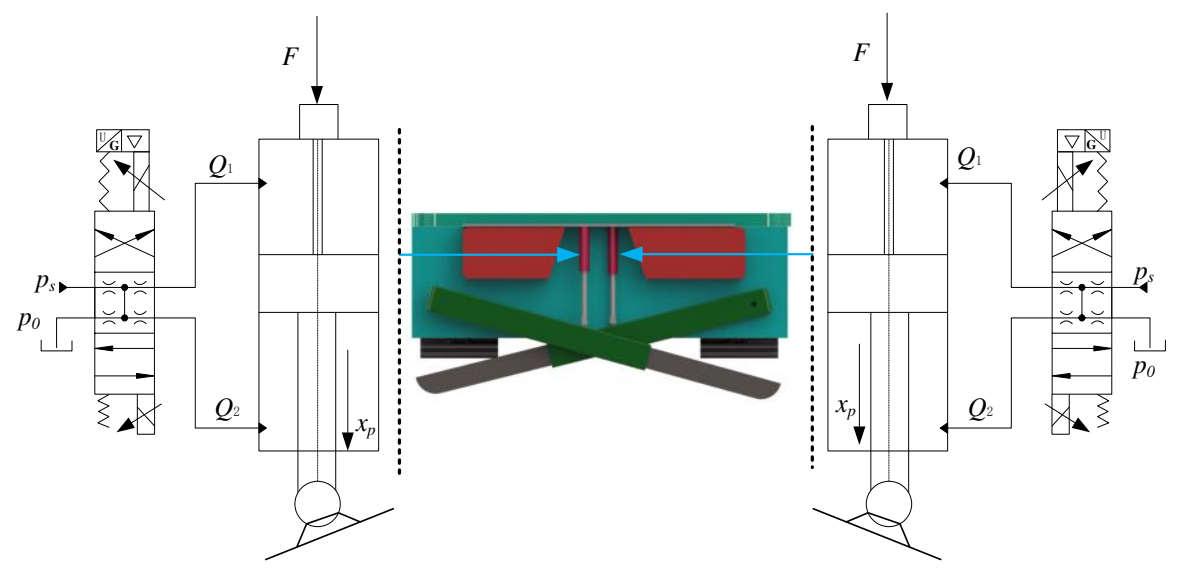

Figure 2 Schematic diagram of valve-controlled asymmetric hydraulic cylinder

In the electro-hydraulic servo system, the load flow $Q_{\mathrm{L}}$ of the control servo valve is a function of the load pressure $P_{\mathrm{L}}$ and the spool displacement $x_{\mathrm{v}}$.

$$
Q_{\mathrm{L}}=f\left(x_{v}, p_{\mathrm{L}}\right)
$$

The steady-state characteristic equation of the ideal zero openings four side spool valve with matched and symmetrical throttle windows is as follows:

$$
Q_{\mathrm{L}}=C_{\mathrm{d}} w x_{v} \sqrt{\frac{1}{\rho}\left(p_{\mathrm{s}}-\frac{x_{v}}{\left|x_{v}\right|}\right) p_{\mathrm{L}}}
$$

Where, $Q_{\mathrm{L}}$-load flow, $\mathrm{m}^{3} / \mathrm{s}$

$w$-Servo valve area gradient, $\mathrm{m}$

$C_{\mathrm{d}}$-Flow coefficient of the valve port

$p_{\mathrm{L}}$-Load differential pressure, $\mathrm{MPa}$

$p_{\mathrm{s}}$-System oil supply pressure, MPa

$\rho$-Oil density, $\mathrm{kg} / \mathrm{m}^{3}$

$x_{v}$ - Servo valve displacement, $\mathrm{m}$

The linearization of the above formula is as follows:

$$
\Delta Q_{\mathrm{L}}=\left.\frac{\partial Q_{\mathrm{L}}}{\partial x_{v}}\right|_{0} \Delta x_{v}+\left.\frac{\partial Q_{\mathrm{L}}}{\partial p_{\mathrm{L}}}\right|_{0} \Delta p_{\mathrm{L}}
$$

Make the following definition:

$$
\begin{gathered}
K_{\mathrm{Q}}=\frac{\partial Q_{\mathrm{L}}}{\partial x_{v}} \\
K_{\mathrm{C}}=-\frac{\partial Q_{\mathrm{L}}}{\partial P_{\mathrm{L}}}
\end{gathered}
$$

Where, $K_{\mathrm{Q}}$ - servo valve flow gain

$K_{\mathrm{c}}$-Flow pressure amplification factor

Then the flow equation of the servo valve is simplified as follows:

$$
Q_{\mathrm{L}}=K_{\mathrm{Q}} x_{v}-K_{\mathrm{C}} p_{\mathrm{L}}
$$

The force balance equation of asymmetric hydraulic cylinder is as follows: 


$$
p_{1} A_{1}-p_{2} A_{2}=m \ddot{x}_{\mathrm{p}}+B_{\mathrm{C}} \dot{x}_{\mathrm{p}}+K x_{\mathrm{p}}+F
$$

Where, $p_{1}$ - the pressure of rodless cavity of hydraulic cylinder

$p_{1}$-Pressure in rod cavity of hydraulic cylinder

$A_{1}$-Effective working area of the piston without rod cavity in hydraulic cylinder

$\mathrm{A}_{2}$-Effective working area of piston with rod cavity in hydraulic cylinder

$K$-Load spring stiffness

$x_{p}$-Displacement of the piston rod of hydraulic cylinder

${ }_{m}$-Total amount of piston and load converted to the piston rod of hydraulic cylinder

$B_{c}$-Viscous damping coefficient of motion

$F$-External arbitrary load force

The flow continuity equation of hydraulic cylinder is as follows:

$$
\left\{\begin{array}{l}
V_{1}=V_{10}+A_{1} x_{p}+C_{i}\left(p_{1}-p_{2}\right)+\beta^{-1}\left(V_{10}-A_{1} x_{p}\right) \dot{p}_{1} \\
V_{2}=V_{20}+A_{2} x_{p}+C_{i}\left(p_{1}-p_{2}\right)+\beta^{-1}\left(V_{10}-A_{1} x_{p}\right) \dot{p}_{2}
\end{array}\right.
$$

Where, $Q_{1}$ - flow into the rodless cavity of the hydraulic cylinder

$Q_{2}$-Flow rate of hydraulic cylinder with rod cavity

$C_{i}$-Internal leakage coefficient

$\beta$-Effective bulk modulus of elasticity of hydraulic oil

$V_{10}$-Initial volume of the cylinder without rod cavity

$V_{20}$-Initial volume of rod cavity of hydraulic cylinder

The volume of two cavities of hydraulic cylinder can be expressed as:

$$
\left\{\begin{array}{l}
V_{1}=V_{10}+A_{1} x_{p} \\
V_{2}=V_{20}+A_{2} x_{p}
\end{array}\right.
$$

Where, $V_{1}$-the volume of the rodless cavity of hydraulic cylinder

$V_{2}$-Volume of rod cavity of hydraulic cylinder

$Q_{\mathrm{L}}=\left(Q_{1}+Q_{2}\right) / 2, \quad p_{\mathrm{L}}=p_{1}-p_{2}$, If the factors of leakage are ignored:

$$
\begin{gathered}
Q_{\mathrm{L}}=A_{m e} \dot{x}_{p} C_{i} p_{L}+4 \beta^{-1} V_{e} \dot{p}_{L} \\
A_{e}=m \frac{\left(1+\eta^{3}\right) A_{1}}{\left(1+\eta^{2}\right)}
\end{gathered}
$$

Where, $A_{m e}=\left(A_{1}+A_{2}\right) / 2=(1+\eta) A_{1} / 2$ is the average piston area; It is the ratio coefficient of the area of the two cavities and the mean value of the equivalent volume of the hydraulic cylinder; Is the equivalent area, is the hydraulic cylinder stroke. By solving equation (6), equation (7) and equation (10) simultaneously, it can be concluded that:

$$
x_{\mathrm{p}}(\mathrm{s})=\frac{K_{Q} x_{v}-\frac{K_{c e}}{A_{e}}\left(\frac{V_{e}}{4 \beta K_{c e}} s+1\right) F}{\frac{V_{e} m}{4 \beta A_{e}} s^{3}+\left(\frac{V_{e} B_{c}}{4 \beta A_{e}}+\frac{K_{c e} m}{A_{e}}\right) s^{2}+\left(\frac{K_{c e} B_{c}}{A_{e}}+A_{m e}\right) s}
$$

Where, $K_{c e}=K_{c}+C_{i}$ is represents the total flow pressure coefficient, which is further analyzed.

$$
V_{e}=\frac{2 V\left(\eta^{3}+\frac{V_{1}}{V}\left(1-\eta^{3}\right)\right)}{\left(1+\eta^{2}\right)}
$$


Where, $V$ is the total volume of the hydraulic cylinder cavity because when the piston of the hydraulic cylinder moves, $V_{1}$ is constantly changing. It can be seen from equation (13) that the equivalent volume $V_{\mathrm{e}}$ of the hydraulic cylinder is also a time-varying value, and the mean value of its change is taken in the above derivation process. Therefore, the precise mathematical model of the valve-controlled electro-hydraulic position system can't be obtained. The system is a typical time-varying system. If the influence of elastic load and external interference force is not considered, and generally $B_{c}$ is small, then $K_{c e} B_{c} / A_{e} \square A_{m e}$, the system model is further simplified as:

$$
\frac{x_{p}(s)}{x_{v}(s)}=\frac{\frac{1}{A_{m e}}}{s\left(\frac{s^{2}}{\omega_{h}^{2}}+\frac{2 \xi_{h}}{\omega_{h}} s+1\right)}
$$

Where, $\xi_{h}=K_{c c} \sqrt{\frac{m \beta}{V_{e} A_{e} A_{m e}}}+\frac{B_{c}}{4} \sqrt{\frac{V_{e}}{A_{e} A_{m e} \beta m}}$ is the damping ratio of hydraulic cylinder, $\omega_{h}=2 \sqrt{\frac{A_{e} A_{m e} \beta}{V_{c} m}}$ is the natural frequency of hydraulic cylinder.

2 Design of electro-hydraulic position servo control system based on improved ADRC

The structure of traditional ADRC is shown in Figure 3, which is mainly composed of tracking differentiator (TD), extended state observer (ESO) and feedback control rate (NLSEF).

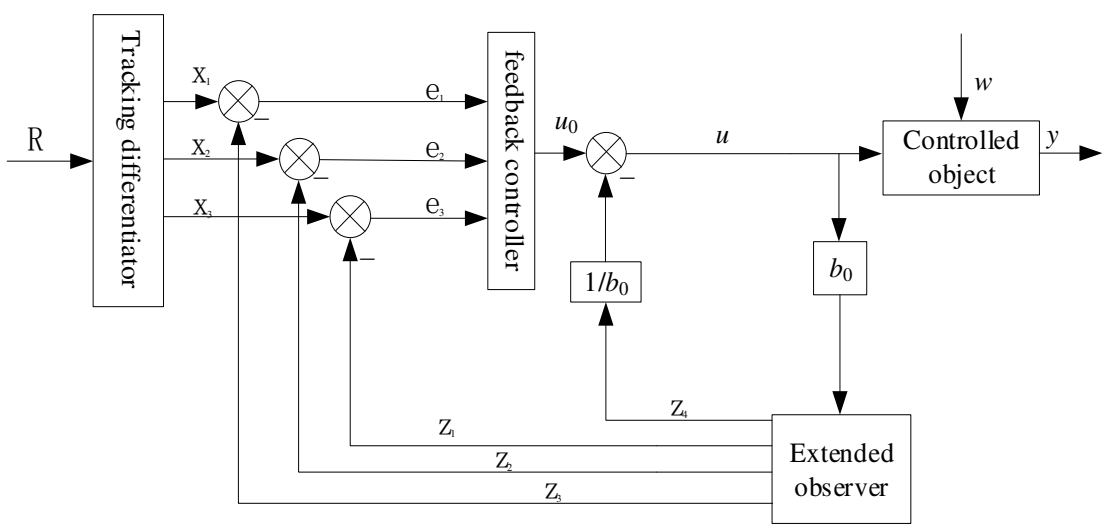

Figure 3 structure diagram of ADRC

According to equation (12), the electro-hydraulic servo position system model is considered as a third-order system, and the traditional ADRC structure is adopted. In the figure above, $\mathrm{R}$ is the given position signal, and the transition process is arranged for $\mathrm{R}$ through $\mathrm{TD}$, which will expand the position signal $x_{1}$, velocity signal $x_{2}$ and acceleration signal $x_{3} ; z_{1}, z_{2}$ and $z_{3}$ are the estimated values of the system states; $z_{4}$ is the estimated value of the total disturbance of the extended ESO system; $e_{1}, e_{2}$ and $e_{3}$ are deviation signals; $b_{0}$ is the compensation factor; $u$ is the control signal; $w$ is interference signal; $y$ is the output signal. According to the analysis of the above parameters, there are many problems in both linear and nonlinear ADRC, such as a large number of parameters to be adjusted, a large number of variables to be observed by the observer, heavy burden.

2.1 variable result active disturbance rejection control

ADRC transforms the system into a pure integrator series structure by estimating and compensating the total disturbance of the system, as shown in equation (15), which is called Han's general form.

$$
y^{(v)}=b u
$$

Where, $v$ is the relative order of the ideal controlled object, and the selection of the relative order of the control object should conform to the corresponding physical meaning as far as possible. 
Reasonable order selection of the controlled object and full use of the known or measurable information of the model can effectively reduce the burden of the observer, reduce the phase delay, improve the observation efficiency, and simplify the structure of the controller. It can be seen from equation (14) that the system is composed of integral link and second-order oscillation link in series, and the integral link plays a leading role. Therefore, according to equation (12) and regarding the servo valve as a proportional link, the block diagram as shown in Figure 4 can be drawn from the control quantity to the output.

In the Electro-hydraulic position servo system, the control quantity generates the current to drive the valve core of the servo valve through the servo amplifier and then changes the displacement of the valve core. The valve port will generate the corresponding flow to act on the hydraulic cylinder. The ratio of the flow to the effective area of the piston is the movement speed. The hydraulic movement speed is the position of the controlled hydraulic cylinder after integration, that is, the actual position of the hydraulic cylinder is calculated according to the speed.

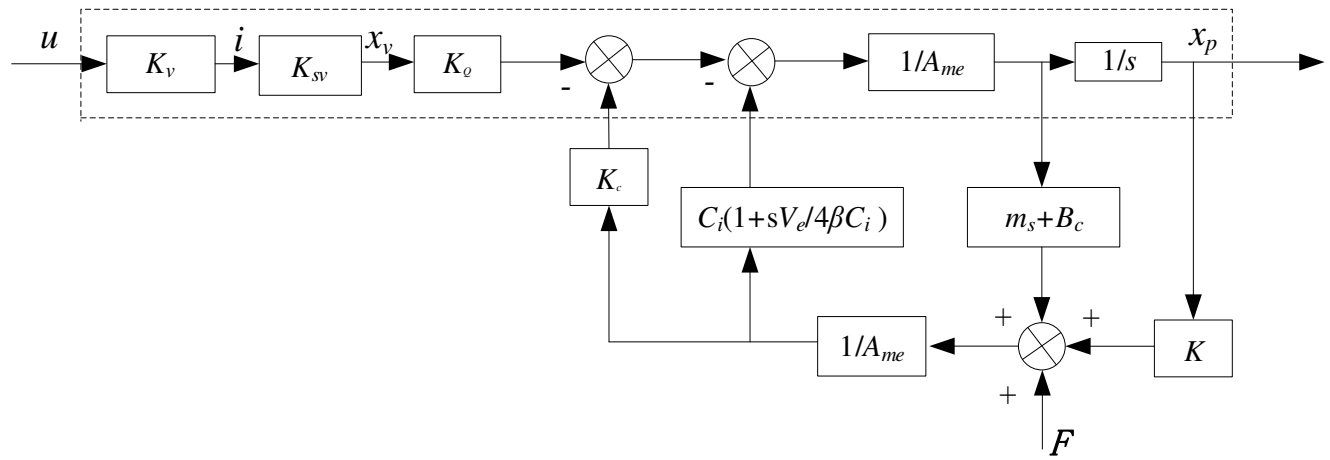

Figure 4 block diagram of electro-hydraulic position servo system

In the above analysis, the system represented by equation (14) is rewritten in the form of a dynamic model as follows:

$$
\dot{x}_{\mathrm{p}}=-\eta_{1} \dddot{x}_{\mathrm{p}}-\eta_{2} \ddot{x}_{\mathrm{p}}+w+b u
$$

Where, ${ }_{w}$ is the unmodeled part, $\eta_{1} 、 \eta_{2}$ is the system parameters, and the higher derivative term of the system and the uncertainty of the model are regarded as the internal uncertainty part, then the total disturbance of the system can be defined as follows:

$$
f=-\eta_{1} \dddot{x}_{\mathrm{p}}-\eta_{2} \ddot{x}_{\mathrm{p}}+w
$$

Furthermore, assuming that $f$ is differentiable, the system represented by equation (16) can be rewritten as a general first-order system, namely equation (18), where $u$ is the system input, $y$ is the system output, $f$ is the total disturbance of the system, and $b$ is the control gain.

$$
\dot{y}=b u+f
$$

According to equation (18), and improved ADRC is adopted. The traditional ADRC algorithm is reconstructed, the output $y$ is regarded as the available information, and the position deviations $e$ and disturbance $f$ are selected as the state variables to reconstruct the ADRC. The system position deviations $e=r-y$ and $r$ are the expected displacement signals. they are substituted into equation (18):

$$
\dot{e}=\dot{r}-y-b u
$$

$$
x_{1}=e, \quad x_{2}=r-f \text { is taken as state variables, then: }
$$




$$
\dot{e}=x_{2}-b u
$$

According to the selected state variables, a second-order nonlinear state observer is constructed:

$$
\left\{\begin{array}{c}
e_{1}=z_{1}-e \\
\dot{z}_{1}=z_{2}-b_{0} u-\beta_{1} \operatorname{fal}\left(e_{1}, a_{1}, \delta\right) \\
\dot{z}_{2}=-\beta_{2} \operatorname{fal}\left(e_{1}, a_{2}, \delta\right)
\end{array}\right.
$$

Where $z_{1}$ is the observed value of deviations $e$ and $x_{2}$ is the observed value of generalized disturbance ${ }_{u} ; b_{0}$ is the system input; $\delta$ is the compensation factor; $a_{1}=0.5, a_{2}=0.25$ is the length of the linear segment interval, which can be adjusted according to the empirical value, or according to the actual situation of the system, $\beta_{1}, \beta_{2}$ is the gain coefficient of NLESO; The algorithm of $f a l\left(e_{1}, a_{2}, \delta\right)$ is as follows

$$
f a l\left(e_{1}, a_{2}, \delta\right)=\left\{\begin{array}{c}
|e| \operatorname{sign}(e),|e|>\delta \\
\frac{e}{\delta^{1-a}},|e| \leq \delta
\end{array}\right.
$$

To eliminate the disturbance, the nonlinear state feedback control law is selected

$$
\left\{\begin{array}{c}
u_{0}=k_{p} f a l\left(e_{1}, a_{3}, \delta\right) \\
u=u_{0}+\frac{z_{2}}{b_{0}}
\end{array}\right.
$$

When the observation deviations of the observer is ignored, $z_{2} \approx x_{2}$, can be expressed as:

$$
u=k_{p} f a l\left(e_{1}, a_{3}, \delta\right)+\frac{\dot{r}}{b_{0}}-\frac{f}{b_{0}}
$$

It is not difficult to find from equation (24) that the control law in the improved ADRC strategy can be similar to the combination of proportional feedback control, input differential feedforward and disturbance compensation in linear control. It has good dynamic and steady-state performance, improves the response speed, smoothes the response curve and weakens the overshoot of the system.

Through the above analysis, the control principle diagram based on the improved ADRC electro-hydraulic servo position system is shown in Figure 5. Compared with the traditional ADRC structure, the known or measurable information of the model is fully utilized. The position deviations is used as the input of the ADRC, so that the ESO can observe the total disturbance of the system, and also observe the differential of the given position signal, To some extent, the lag problem caused by ESO observation is reduced. On the one hand, the disturbance compensation is realized. On the other hand, differential feedforward is introduced, which can not only improve the response speed of the system but also reduce overshoot. The third order ADRC is transformed into the first order ADRC. The system has only 4 parameters to be adjusted, $\beta_{1}, \beta_{2}, b_{0}, k_{p}$, which makes the parameters easy to set and the control algorithm is simpler and easier to implement.

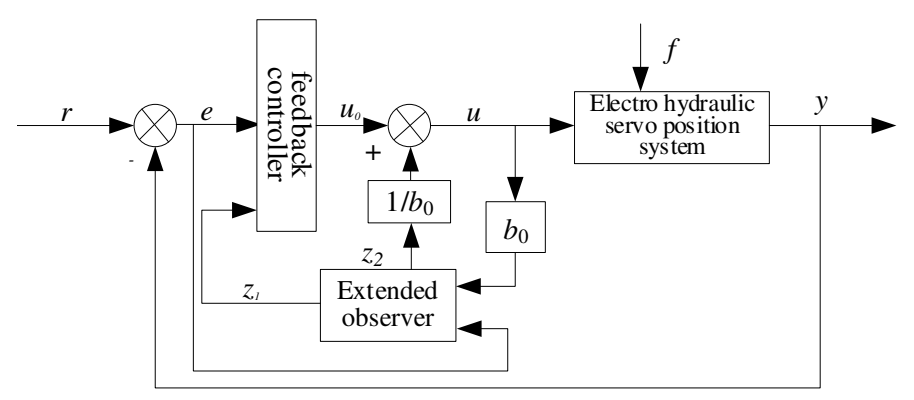

Figure 5 Schematic diagram of improved ADRC 


\section{Simulation Analysis}

To get closer to the real operating conditions of the system, the simulation model of the system is built in the environment of MATLAB/Simulink and AMESim. The design of simulation parameters is shown in Table 1.

Firstly, the $40 \mathrm{~mm}$ step signal is used as the position command of the system, and the system response comparison curve is obtained, as shown in Figure 6. According to the graph observation, the response time of the improved ADRC algorithm to the expected position is about 1.1s, the traditional ADRC is about $1.21 \mathrm{~s}$, and the PID control mode is about $1.25 \mathrm{~s}$. The dynamic response speed of the system using the improved ADRC algorithm is $47.62 \%$ higher than that before the improvement, $60 \%$ higher than that of the PID, and the steady-state accuracy is also improved.

Table 1 simulation parameters

\begin{tabular}{|c|c|}
\hline Parameter name & Numerical value \\
\hline Hydraulic cylinder stroke /m & 0.499 \\
\hline Static friction $/ \mathrm{N}$ & 119 \\
\hline Piston rod diameter $/ \mathrm{m}$ & 0.0295 \\
\hline Supply pressure /MPa & 20.9 \\
\hline Piston diameter $/ \mathrm{m}$ & 0.04 \\
\hline Viscous friction $/ \mathrm{N} \cdot \mathrm{m} \cdot \mathrm{s}^{-1}$ & 119.9 \\
\hline Load quality $/ \mathrm{kg}$ & 250.01 \\
\hline Servo valve flow $/ \mathrm{L} \cdot \mathrm{min}^{-1}$ & 80.1 \\
\hline Curie friction $/ \mathrm{N}$ & 100.1 \\
\hline The damping ratio of a servo valve & 0.781 \\
\hline Internal leakage $/ \mathrm{L} \cdot \min \cdot \mathrm{MPa}^{-1}$ & $4 e-4$ \\
\hline Servo valve frequency $/ \mathrm{Hz}$ & 50 \\
\hline 501 & 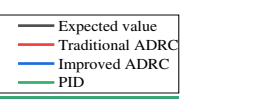 \\
\hline $\begin{array}{ccccccc}0.0 & 0.5 & 1.0 & 1.5 & 2.0 & 2 . \\
& & & & & & \\
& & & \end{array}$ & $\begin{array}{llll}5 & 3.0 & 3.5 & 4.0\end{array}$ \\
\hline
\end{tabular}

Fig. 6 comparison curve of a system step response

Furthermore, given the system $r=50 \times \sin (0.5 \pi t)+100$ sinusoidal position signal, the position tracking simulation waveform is shown in Figure 7, and the deviations comparison curve is shown in Figure 8. The maximum deviation of the improved ADRC control strategy is about $2.5 \mathrm{~mm}$, the maximum deviation of the traditional ADRC algorithm is about $4.5 \mathrm{~mm}$, and the maximum deviation of the PID control mode is about $6 \mathrm{~mm}$. Compared with the PID control, the deviations of the improved ADRC control is reduced by $58.34 \%$. The observer observation curves $z_{1}$ and $z_{2}$ are shown in Figure 9 and Figure 10 respectively.

Finally, in order to verify the anti-disturbance ability of the designed controller, External force disturbance of sinusoidal signal with frequency $1 \mathrm{~Hz}$ and amplitude $10000 \mathrm{~N}$ is added to the load end of AMESim simulation model, still tracking sine position, the system response curve is shown 
in Figure 11. The error comparison curve is shown in Figure 12, In case of external interference, The maximum error of PID control is $9 \mathrm{~mm}$, the maximum error of traditional ADRC is about 5 $\mathrm{mm}$, and the maximum error of improved ADRC control is about $3 \mathrm{~mm}$, The anti-interference ability is better than that of PID control, which is equivalent to that of traditional ADRC. The curve after adding disturbance is shown in Figure 13 and Figure 14.

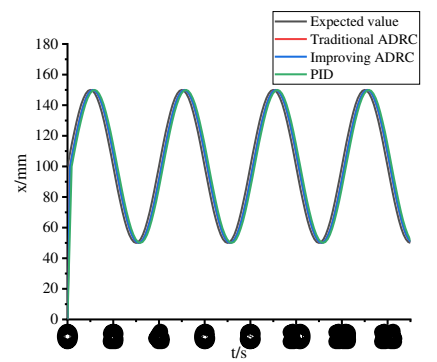

Fig. 7 undisturbed position tracking curve

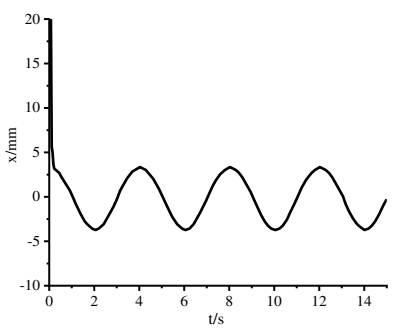

Fig. 9 deviations observation $\mathrm{z}_{1}$ output curve

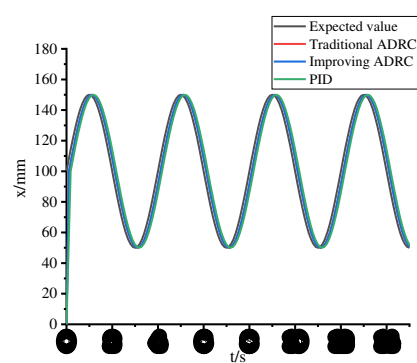

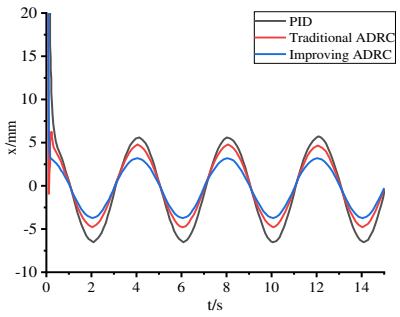

Fig. 8 deviations tracking comparison curve

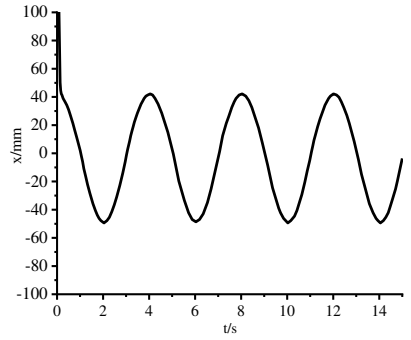

Fig. 10 total disturbance estimation $\mathrm{z}_{2}$ curve

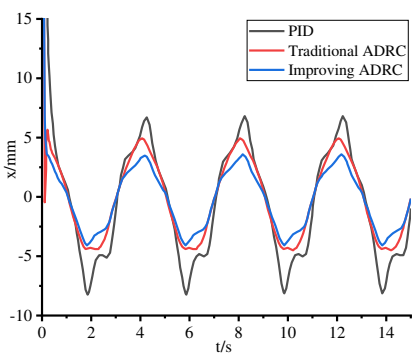

Fig. 11 position tracking curve after scrambling Fig. 12 comparison curve of deviations tracking after scrambling
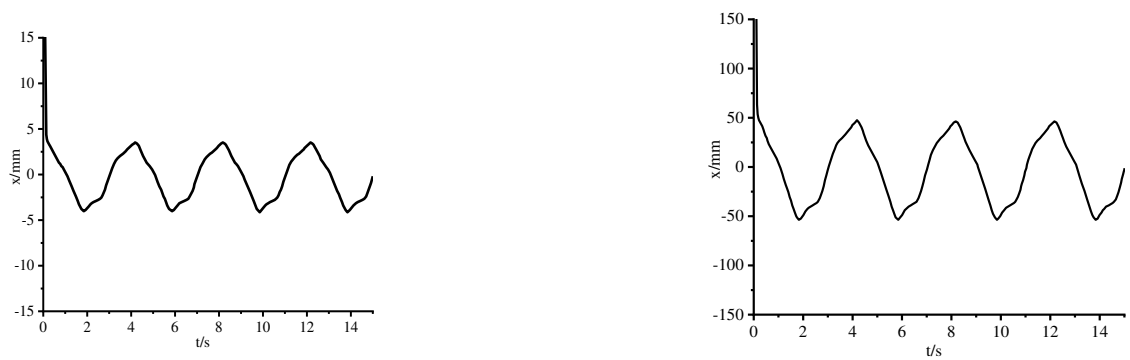

Fig.13 output curve of deviations observation $\mathrm{z}_{1}$ after scrambling Fig.14 the curve of total disturbance estimation $\mathrm{z}_{2}$ after scrambling

4 Conclusion

To solve the adverse effects of the uncertain parameters and unknown disturbance in the electro-hydraulic servo system, this paper proposes an improved nonlinear ADRC method based on the positioning system of an electro-hydraulic servo. Through modeling and analyzing the valve control asymmetrical hydraulic system, the ADRC applied to the electro-hydraulic servo position system is designed as the first-order nonlinear ADRC. The algorithm is simple and easy to realize, 
which greatly reduces the design difficulty of the controller, and makes full use of the known information of the system to take the input and output deviations of the system as the input of the controller, The simulation results show that the first-order nonlinear ADRC has good dynamic performance and steady-state precision, and has good inhibition ability to nonlinear and unknown disturbance, which provides some reference for the use of self-disturbance rejection control in the electro-hydraulic servo system.

Reference:

[1] ZHANG Lijie, GUO Fei, LI Yongquan, et al. Global dynamic modeling of electro-hydraulic 3-UPS/S parallel stabilized platform by bond graph[J]. Chinese Journal of Mechanical Engineering, 2016, 29(6): 1-10.

[2] PRIETO P J, CAZAREZ-CASTRO N R, AGUILAR L T, et al. Fuzzy slope adaptation for the sliding mode control of a pneumatic parallel platform[J]. International Journal of Fuzzy Systems, 2017, 19(1): 167-178.

[3] MOHAMMED A M, LI Shuai. Dynamic neural networks for kinematic redundancy resolution of parallel Stewart platforms[J]. IEEE Transactions on Cybernetics, 2015, 46(7): 1538-1550.

[4] KHALID A, ZEB K, HAIDER A. Conventional PID, adaptive PID, and sliding mode controllers design for aircraft pitch control[C]// 2019 International Conference on Engineering and Emerging Technologies (ICEET). IEEE,2019:1-6.

[5] Yuan X D, Xie Y C, Hua J H. Research on PID Control of Electro-Hydraulic Position Servo Control System Based on SDO Optimization[J]. Advanced Materials Research, 2014, 926-930:1396-1399.

[6] Wang X, Shen Z, Chen S, et al. Research on the Pressure Impact Characteristic of Continuous Rotary ElectroHydraulic Servo Motor[J]. IEEE Access, 2019.

[7] Nguyen M H, Dao H V, Ahn K K. Active Disturbance Rejection Control for Position Tracking of ElectroHydraulic Servo Systems under Modeling Uncertainty and External Load[J]. Actuators, 2021, 10(2):20.

[8] Lee W, Yoo S, Nam S, et al. Passivity-Based Robust Compliance Control of Electro-Hydraulic Robot Manipulators with Joint Angle Limit[J]. IEEE Robotics and Automation Letters, 2020, PP(99):1-1.

[9] Peng H, Wu M, Lu H, et al. A Distributed Strategy to Attitude Following of the Multi-DOF Parallel Electrical Manipulator Systems[J]. IEEE Transactions on Industrial Electronics, 2021, PP(99):1-1.

[10] Hao Z, Yang Y, Gong Y, et al. Linear/Nonlinear Active Disturbance Rejection Switching Control for Permanent Magnet Synchronous Motors[J]. IEEE Transactions on Power Electronics, 2021, PP(99):1-1.

[11] Fan Y, Shao J, Sun G, et al. Active Disturbance Rejection Control Design Using the Optimization Algorithm for a Hydraulic Quadruped Robot[J]. Computational Intelligence and Neuroscience, 2021, 2021(12):1-22.

[12] Shen W, Shen C. An extended state observer-based control design for electro-hydraulic position servomechanism[J]. Control Engineering Practice, 2021, 109(1):104730.

[13] Mohorcic J, Dong L. Extended state observer-based pressure control for pneumatic actuator servo systems[J]. 2021.

[14] Chen Z, Zhao Y. Active Disturbance Rejection Control for Hypersonic Flutter Suppression Based on Parametric ROM[J]. Journal of Aerospace Engineering, 2020, 33(6):04020083. 